\title{
Helicase-like transcription factor expression is associated with a poor prognosis in Non-Small-Cell Lung Cancer (NSCLC)
}

\author{
Ludovic Dhont ${ }^{1,2,3}$, Melania Pintilie ${ }^{4}$, Ethan Kaufman², Roya Navab², Shirley Tam², Arsène Burny ${ }^{5}$, \\ Frances Shepherd ${ }^{6}$, Alexandra Belayew ${ }^{1}$, Ming-Sound Tsao ${ }^{2,6,7}$ and Céline Mascaux ${ }^{8,9^{*}}$
}

\begin{abstract}
Background: The relapse rate in early stage non-small cell lung cancer (NSCLC) after surgical resection is high. Prognostic biomarkers may help identify patients who may benefit from additional therapy. The Helicase-like Transcription Factor (HLTF) is a tumor suppressor, altered in cancer either by gene hypermethylation or mRNA alternative splicing. This study assessed the expression and the clinical relevance of wild-type (WT) and variant forms of HLTF RNAs in NSCLC.

Methods: We analyzed online databases (TCGA, COSMIC) for HLTF alterations in NSCLC and assessed WT and spliced HLTF mRNAs expression by RT-ddPCR in 39 lung cancer cell lines and 171 patients with resected stage I-II NSCLC.

Results: In silico analyses identified HLTF gene alterations more frequently in lung squamous cell carcinoma than in adenocarcinoma. In cell lines and in patients, WT and I21R HLTF mRNAs were detected, but the latter at lower level. The subgroup of 25 patients presenting a combined low WT HLTF expression and a high I21R HLTF expression had a significantly worse disease-free survival than the other 146 patients in univariate (HR 1.96, Cl 1.17-3.30; $p=0.011$ ) and multivariate analyses (HR 1.98, Cl 1.15-3.40; $p=0.014$ ).
\end{abstract}

Conclusion: A low WT HLTF expression with a high I21R HLTF expression is associated with a poor DFS.

Keywords: Non-small cell lung cancer, HLTF, Prognosis, Alternative splicing

\section{Background}

Lung cancer is responsible for the highest cancerassociated mortality rate worldwide. Only $16 \%$ of patients affected with Non-small cell lung cancer (NSCLC), which is the most common subtype, are alive 5 years after diagnosis, and this number has hardly improved over several decades [1]. One reason for this poor prognosis is that only $15 \%$ of lung cancers are diagnosed at an early stage. Till recently the standard of care for NSCLC at stages I-IIIA was surgery, resulting in patient survival rates of $23 \%$ in stage IIIA, $33 \%$ in stage

\footnotetext{
* Correspondence: celinejmmascaux@gmail.com

${ }^{8}$ Department of Muldisciplinary Oncology and Therapeutic Innovations, Assistance Publique des Hôpitaux de Marseille (AP-HM), Aix-Marseille University, Chemin des Bourrely, 13195 Marseille, Cedex 20, France

${ }^{9}$ Centre de Recherche en Cancérologie de Marseille (CRCM, Cancer Research Center of Marseille), Inserm UMR1068, CNRS UMR7258 and Aix-Marseille University UM105, Marseille, France

Full list of author information is available at the end of the article
}

IIB, and up to $89 \%$ in stages IA [2]. Adjuvant chemotherapy after radical resection of localized NSCLC improves survival at 5 years by about $5 \%$ [3]. However, there is still a relatively high risk of relapse, and up to $40 \%$ of all stage IB and $60 \%$ of stage II patients die from their disease despite receiving adjuvant chemotherapy [4]. The integration of prognostic and predictive biomarkers has the potential of identifying patients who are at a low-risk of relapse following surgery and do not need further therapy, and conversely, patients who are at a high risk of relapse and who potentially may derive the greatest benefit from adjuvant treatment, including chemotherapy or personalized treatment based on individual tumor profiling. Therefore, an effort to identify more robust prognostic and predictive biomarkers is needed [5].

The Helicase-like Transcription Factor (HLTF) is a member of the yeast mating SWItch/Sucrose Non Fermenting (SWI/SNF) family of proteins involved in 
chromatin remodeling. Several studies demonstrated its function in gene transcription [6], cell cycle [7], DNA repair $[8,9]$, and genome stability maintenance [10], supporting its tumor suppressor role. In cancer, two different alterations in HLTF expression were reported: (i) an epigenetic silencing by hypermethylation of its promoter and (ii) an alternative splicing of its mRNA, leading to the production of several shorter forms of the protein lacking DNA repair domains. The hypermethylation of HLTF promoter was first identified in colon cancer [11] and was reported in other types of cancers, including gastric cancers [12-16]. It was shown in HeLa cells that HLTF mRNA was alternatively spliced in the exons 19 to 22 region, resulting in the expression of shorter truncated protein forms. The distinctive character of the HLTF spliced mRNA variants (I21R) is that they contain the intron 21 between exons 21 and 22. To date, the expression of HLTF protein forms was reported in head and neck, cervix and thyroid [17-20] cancers and associated with a poor prognosis [16].

In lung cancer, one study assessed the hypermethylation of HLTF in a cohort of 54 patients with NSCLC [21]. Promoter hypermethylation was found in 21 patients (39.6\%), including 9/20 squamous cell carcinoma (SCC) and 12/33 adenocarinoma (ADC). Patients whose tumors harboured HLTF hypermethylation had shorter survival, in comparison with patients whose tumors had a hypomethylated HLTF promoter (log-rank, $p=0.035$ ). So far, to our knowledge, there are no published data about the expression of HLTF (wild-type and its truncated forms) in lung cancer.

The purpose of this study is to assess the expression of wild-type (WT) and spliced variants (I21R) of HLTF mRNAs in NSCLC and evaluate their clinical relevance. We analyzed publicly available databases for HLTF in lung cancer and assessed its expression in NSCLC cell lines and in a clinically annotated cohort of 171 patients with resected stage I-II NSCLC.

\section{Methods}

\section{In silico analyses}

Available genomic profiling data (mutation, copy number, DNA methylation [correlation only], and mRNA expression) for HLTF were downloaded from cBioPortal, an online portal for accessing data from The Cancer Genome Atlas (TCGA) project and other cancer genome profiling initiatives (http://www.cbioportal.org/publicportal). Additional cancer genome profiling data were obtained from the Catalogue of Somatic Mutations in Cancer (http://cancer.sanger.ac.uk/cosmic; [22]).

To obtain gene expression estimates for individual mRNA forms, paired-end RNAseq raw read data from the TCGA project were downloaded from the Cancer Genomics Hub (https://cghub.ucsc.edu/). In brief, reads were mapped to the latest human reference assembly, hg19, using TopHat, a splice-aware short-read aligner (http://ccb.jhu.edu/software/tophat). Alignment output was then supplied to Cufflinks (http://cufflinks.cbcb. umd.edu/), which was run in the reference-guided mode to quantify the abundance of known transcripts as well as predict and estimate expression of novel isoforms. Pre- and post-alignment quality control was performed with FastQC (http://www.bioinformatics.babraham.ac.uk /projects/fastqc/) and RSeQC (http://rseqc.sourceforge. net/), respectively.

\section{Patient characteristics}

A total of 171 patients with resected stage I-II NSCLC collected at University Health Network (Toronto, Canada) were included in this study. These patients had surgery between 1996 and 2005. The length of followup: median 5.4 years, range $0.1-12$ years. As these patients all underwent surgery before 2005, none of them received adjuvant chemotherapy as it did only become standard after 2005. The clinical and demographic characteristics of the patient cohort are listed in Table 2.

\section{Cell lines and cell culture}

NSCLC cell lines were purchased from the American Type Cell Collection (ATCC, http://www.atcc.org), and cultured according to ATCC recommendation. Among these, there were 33 of the adenocarcinoma (ADC) subtype (H1693, H2122, H2228, H2279, H1573, H1395, H522, H1792, H838, H1819, H4011, H2291, H2073, H1568, H920, H1993, H4006, HCC827, H3255, H23, H4019, H2126, H1437, H1944, H2009, H2405, H1373, H1355, H1975, HCC2935, A549, H650, H1650), two large cell carcinoma (H661, H4017), one mixed adenosquamous carcinoma (H647) and two of undefined histology (DFC1032, DFC1024). MGH7 cells (squamous cell carcinoma, SCC) were cultured as described [23].

\section{mRNA expression}

Total RNA was extracted from cell lines with RNeasy Mini Kit (QIAGEN) according to the manufacturer's instructions. RNA purity and concentration were assessed with Nanodrop (Thermo Scientific). Total RNA (input $150 \mathrm{ng}$ ) extracted from cell lines and patient tumours were reverse transcribed into cDNA (SuperScript III, Invitrogen). Droplet Digital polymerase chain reaction (ddPCR) was performed based on the manufacturer's recommendations (QX200, Bio-Rad). ddPCR is a highly sensitive qPCR due to a step of sample fractioning (limiting dilutions) by generation of droplets (water:oil emulsion). It allows retrieving an absolute count of RNA copies for each sample, and is particularly indicated for low-expressed targets. Each ddPCR was performed with $22.5 \mathrm{ng}$ cDNA in triplicates. Reaction conditions were as 
follow: ddPCR cycle was set up at $95{ }^{\circ} \mathrm{C}$ for $5 \mathrm{~min}, 40 \mathrm{cy}$ cles of $\left[30 \mathrm{~s}\right.$ at $95{ }^{\circ} \mathrm{C}$ and $1 \mathrm{~min}$ at $58{ }^{\circ} \mathrm{C}$ ], $5 \mathrm{~min}$ at $4{ }^{\circ} \mathrm{C}$, and finally $5 \mathrm{~min}$ at $90{ }^{\circ} \mathrm{C}$. Results were analyzed with QuantaSoft (Bio-Rad), and the cut-off to define positive and negative droplets was set up at 10,000 arbitrary units of fluorescence amplitude. This signal is then used in the calculation of HTLF copy number by a Poisson regression (QuantaSoft, Bio-Rad).

Primers to detect either WT HLTF mRNA (F: 5'-GTT CAAAGATTAATGCGCT-3' and R: 5'-AAAGACAGGA ATGTTGTAAACTGAGA-3') or HLTF mRNA variants I21R (F: 5'-TCCAGTTTCAAAGGTAAAGTACTC-3' and R: 5'-GCCAGTGGTCAACAACAGAA-3') by ddPCR were designed with Primer3 and purchased from Eurogentec. Primers were tested for nonspecific amplicons and primer dimers by visualizing PCR products on $1 \%$ agarose gels and droplet distribution profile (QuantaSoft, Bio-Rad).

\section{Statistical analyses}

Expression levels of different variants of HLTF were measured in triplicates. The reliability was assessed by calculating the intra-class correlation coefficient (ICC) based on the within and between variances estimated using the variance component analysis. For the outcome analysis, the three replicates were averaged for each sample. Two outcome variables were assessed: overall survival (OS) and disease-free survival (DFS). Both were measured from surgery date. For OS, the time was calculated up to the date of death or last follow-up with death of any cause as an event; for DFS, the time was calculated up to the date of relapse, death or last followup with death or relapse as events. There were 71 deaths (number of events for OS) and 81 events for DFS in the cohort. The averages of the three replicates of WT and I21R HLTF expressions were tested for their associations with OS and DFS using the Cox proportional hazards regression. Both variants of HLTF were also dichotomized at their respective medians and were tested as categorical variables using the log-rank test. The percentages for OS and DFS for the high and low values of each of these covariates were calculated using the Kaplan-Meier method. A composite covariate was created by combining WT and I21R HLTF expression levels and a datadriven covariate was defined as "Low WT HLTF and High I21R HLTF" vs. the rest. This new covariate was also tested for its association with OS and DFS by employing the log-rank test. These covariates were tested for their association with outcome, adjusting the model for age $(\leq 65,>65)$, sex, stage (I vs. II), and histology (ADC vs. the rest) using Cox regression. All $p$-values were based on the Wald test. HLTF expressions (continuous) were also tested for their associations with the clinical factors (age, sex, histology, and stage) using the Mann-Whitney test. A cut-off of $\mathrm{p} \leq 0.05$ was used for statistical significance.

\section{Results}

In silico analysis of HLTF alterations in NSCLC

We collected available online data for HLTF alterations in NSCLC from TCGA (Lung ADC and SCC, TCGA Provisional 2015/02/04) and COSMIC, focusing on mutations, copy number alterations (CNAs), and methylation data. We analyzed these data in association with HLTF expression. The type and the frequency of the different HLTF alterations in ADC and SCC are reported in Table 1 . When all types of molecular alteration were considered, HLTF was more frequently altered in SCC (438/504 cases, $83 \%)$ than ADC (266/578 cases, $46.0 \%$; $p<0.0001)$. While a high expression of HLTF was more frequently reported in SCC than in ADC $(28.6 \%$ vs $7.5 \%$, $p<0.0001$ ), a negative correlation between HLTF expression and its methylation status was found in both SCC (Pearson: -0.475 and Spearman: -0.484 ; Fig. 1) and ADC (Pearson: -0.473 and Spearman: - 0.420; Fig. 1). HLTF copy number gain was more frequent in SCC ( $57 \%$ vs $23.3 \%, p<0.0001$ ) as well as high amplifications (26.1\% s $2.1 \%, p<0.0001)$. Conversely, loss of heterozygosity was more frequent in ADC than in SCC $(22.3 \%$ vs $2.9 \%$, respectively, $p<0.0001$ ), along with diploidy (52\% vs $13.5 \%$, respectively, $p<0.0001)$. HLTF mutation is a rare event both in ADC and SCC, 2.2 and 1.5\%, respectively (Table 1). The majority of the 13 mutations (12 missense and 1 splice site mutation) reported in ADC

Table 1 HLTF alterations in lung adenocarcinoma and squamous cell carcinoma

\begin{tabular}{|c|c|c|c|}
\hline & $\begin{array}{l}\text { Adenocarcinoma } \\
(n=578) \\
\text { Number of } \\
\text { cases, } \mathrm{n}(\%)\end{array}$ & $\begin{array}{l}\text { Squamous cell } \\
\text { carcinoma } \\
(n=504) \\
\text { Number of } \\
\text { cases, } n(\%)\end{array}$ & $\begin{array}{l}P \text {-value } \\
\text { (Fisher } \\
\text { test) }\end{array}$ \\
\hline Mutation & $13(2.2 \%)$ & $8(1.5 \%)$ & 0.5110 \\
\hline \multicolumn{4}{|l|}{ Copy number alterations } \\
\hline Homozygous deletion & $1(0.1 \%)$ & $1(0.2 \%)$ & 1.00 \\
\hline Heterozygosity loss & $115(22.3 \%)$ & $15(2.9 \%)$ & $<0.0001$ \\
\hline Diploid & $268(52.0 \%)$ & $68(13.5 \%)$ & $<0.0001$ \\
\hline Gain & $120(23.3 \%)$ & $286(57.0 \%)$ & $<0.0001$ \\
\hline $\begin{array}{l}\text { High level of } \\
\text { amplification }\end{array}$ & $11(2.1 \%)$ & $131(26.1 \%)$ & $<0.0001$ \\
\hline No data & 63 & 3 & \\
\hline \multicolumn{4}{|l|}{ mRNA expression level } \\
\hline High expression & $43(7.5 \%)$ & $141(28.6 \%)$ & $<0.0001$ \\
\hline Low expression & $0(0.0 \%)$ & $6(1.2 \%)$ & 0.0101 \\
\hline
\end{tabular}

Total number of altered cases

$266(46.0 \%) \quad 438(83.0 \%) \quad<0.0001$

Data collected from TCGA database 


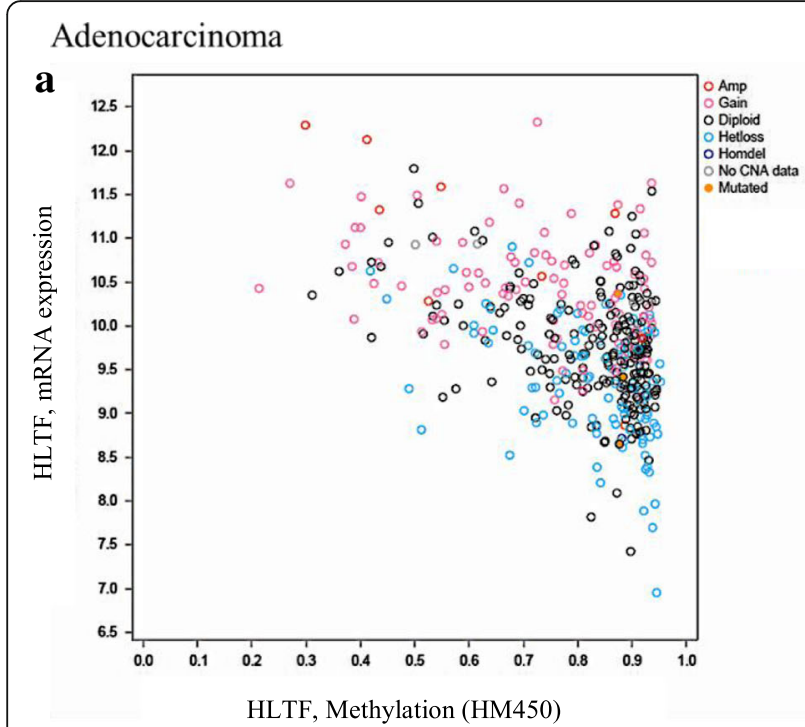

Squamous cell carcinoma

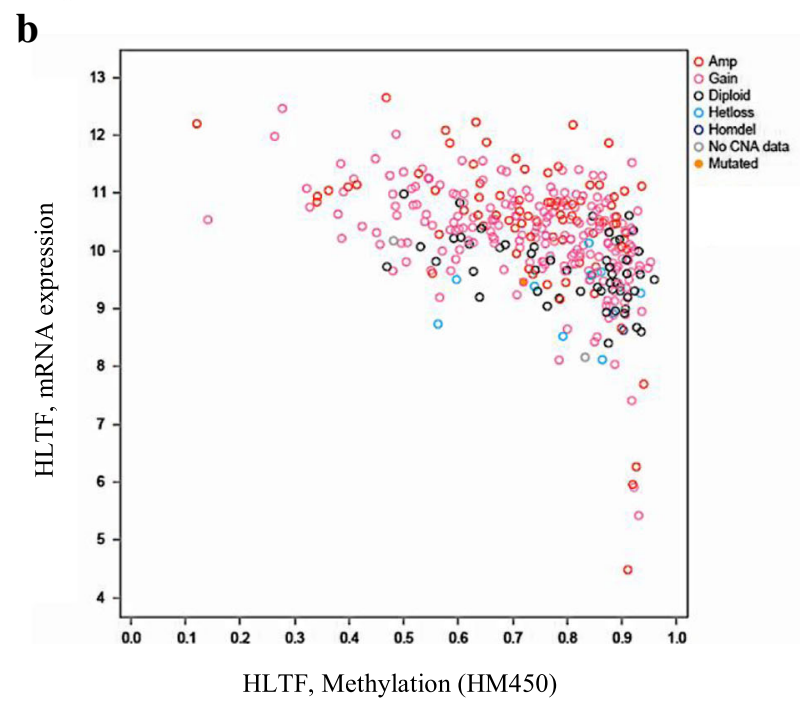

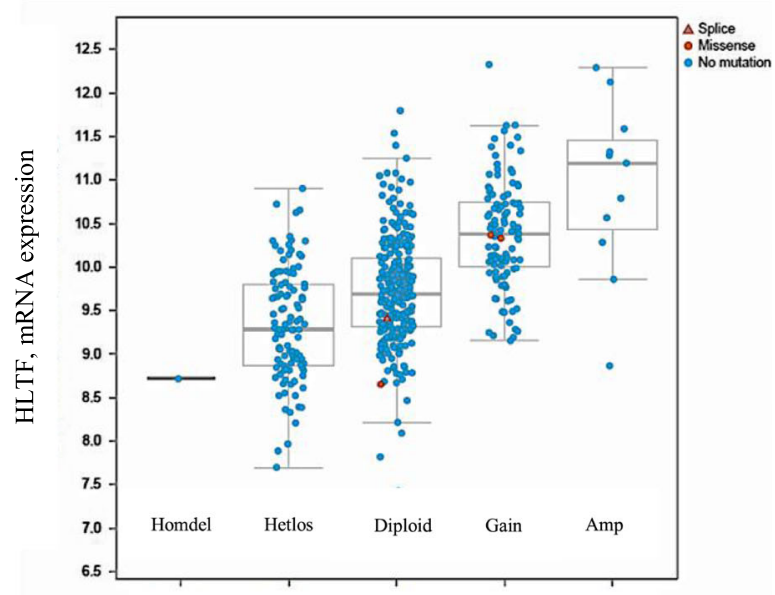

HLTF, Putative copy-number alterations (GISTIC)

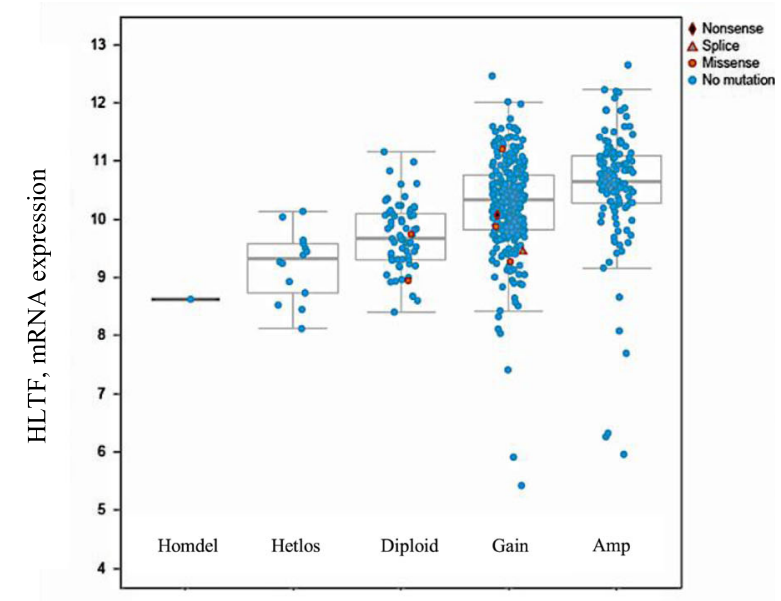

HLTF, Putative copy-number alterations (GISTIC)

Fig. 1 Distribution of NSCLC tumors associated with HLTF expression. a Adenocarcinoma. b Squamous cell carcinoma. HLTF expression according to HLTF methylation (left panels) and copy number alterations (CNA) (right panels)

and 8 mutations (6 missense, 1 splice site and 1 nonsense mutations) in SCC are found in regions encoding functional domains involved in DNA binding (HIRAN domain), Sp1/Sp3 interaction (carboxyl-terminal domain), and DNA repair (SNF2_N/helicase-ATPase and RING finger domains) (Fig. 2).

\section{In vitro screening of HLTF mRNA expression in a panel of NSCLC cell lines}

We assessed HLTF mRNA expression in 39 NSCLC cell lines. Measurements for WT and I21R HLTF were considered reliable based on ICC values $(0.878$ and 0.933 , respectively). Overall, the level of WT HLTF expression was significantly higher than the level of I21R HLTF expression (Fig. 3) (median 71.5 vs. 18.3 respectively, Wilcoxon signed-rank test, $p=4.5 \times 10^{-7}$ ).

\section{Assessment of HLTF expression in a cohort of 171 patients with NSCLC}

HLTF expression was assessed by RT-ddPCR in 171 tumours from patients with surgically resected stage I-II NSCLC. Patient data are summarized in Table 2. Measurements for WT and I21R HLTF were considered reliable based on ICC values $(0.984$ and 0.846 , respectively). As in NSCLC cell lines, the level of WT HLTF expression was significantly higher than the level of I21R HLTF expression in tumours of patients with NSCLC (Fig. 3) when considering all patients (median 20.6 vs. 2.2 respectively, Wilcoxon signed-rank test, $p=2.2 \times 10^{-16}$ ). 
a Adenocarcinoma

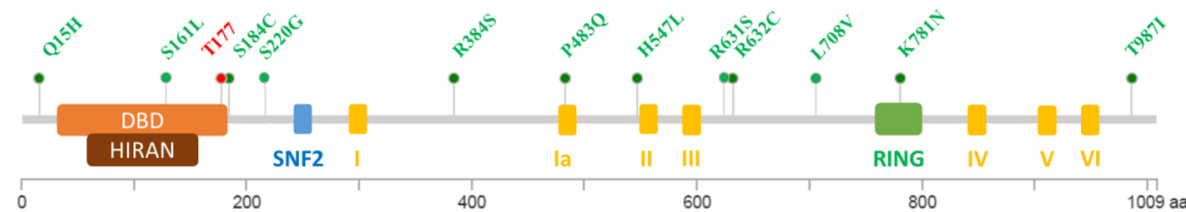

b Squamous cell carcinoma

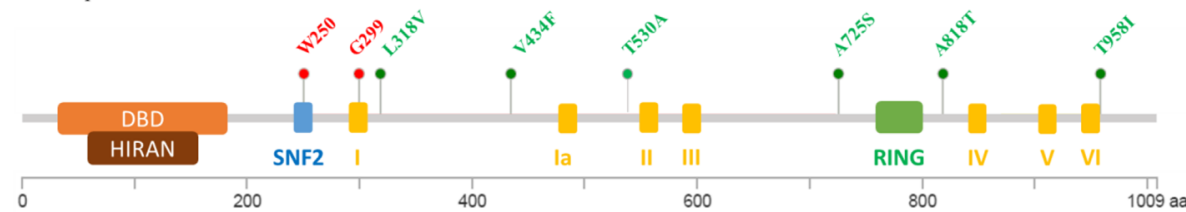

Fig. 2 HLTF mutations in NSCLC. a. Lung adenocarcinoma. b. Lung squamous cell carcinoma. Mutation data were retrieved from TCGA and COSMIC databases. HLTF protein is depicted as a grey line with its functional domains: DNA binding domain (DBD, orange box), HIRAN (brown box), SNF2 (blue box), Helicase/ATPase I-III (yellow boxes), zinc finger RING (green box). Under the protein is a scale showing the amino-acid size. Mutation are depicted by colored dots (missense: green; spliced or stop mutation: red) with their position and the residue change

There was no difference between SCC and ADC for WT and I21R HLTF expressions ( $p=0.09$ and 0.17 , respectively). Overall, the level of HLTF expression was lower in tumours from patients than in cell lines (WT HLTF: 20.6 vs. $71.5, p=9.3 \times 10^{-11}$ and I21R HLTF: 2.2 vs. 18.3 , $p=2.8 \times 10^{-12}$, Wilcoxon rank-sum test; Fig. 3).

\section{HLTF and clinical characteristics}

WT and I21R HLTF expressions were first tested for their association with patient clinical characteristics (age, sex, histology, and stage). There was no association with these characteristics and HLTF expression (Table 2).
Second, we considered a composite covariate combining WT and I21R HLTF expressions dichotomized at their median levels. Four groups were built accordingly. There was no association with patient clinical characteristics (Table 3).

\section{HLTF expression and outcome}

A univariate analysis (Cox proportional hazard regression model and log-rank test) was first performed to assess the association between WT and I21R HLTF expression levels, and OS and DFS. The mRNA expression measures were sequentially considered as continuous and as dichotomous variables. There was no
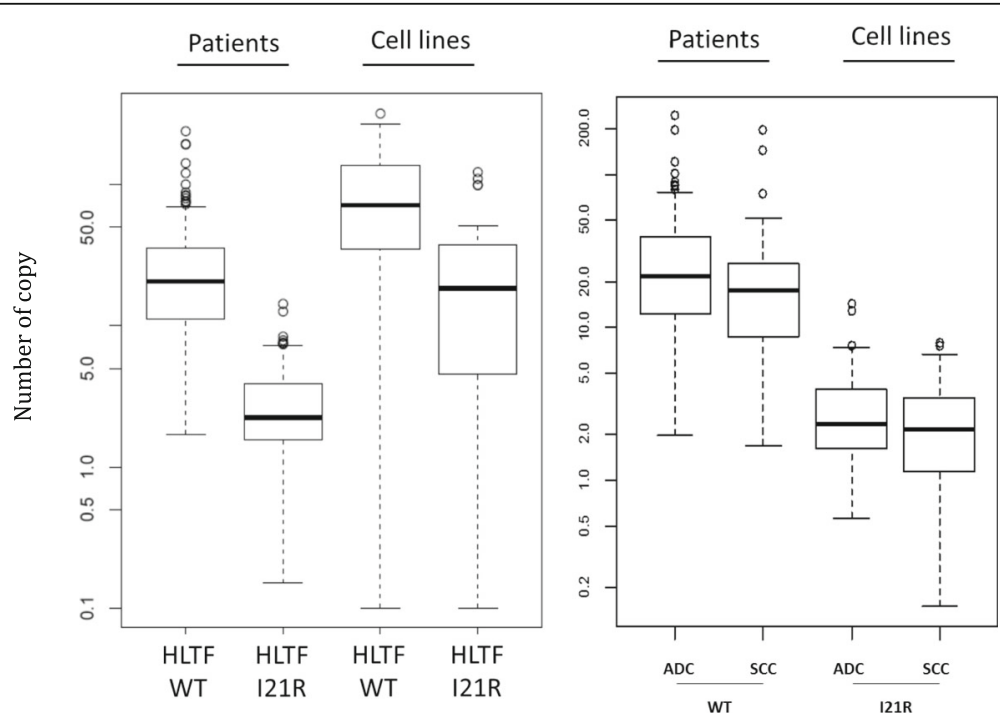

Fig. 3 Distribution of WT and I21R HLTF expressions (number of copy) in lung adenocarcinoma (ADC) (left panel) and squamous cell carcinoma (SCC) (right panel) patients and cell lines. RNA from cell lines and tumors was extracted and reverse transcribed. A ddPCR was performed to detect WT and I21R HLTF expression by using specific primer sets. The high sensitivity of ddPCR provides an absolute count of RNA copies for each sample, displayed in $\mathrm{Y}$-axis 
Table 2 Association of WT HLTF and I21R HLTF expressions with patient clinical characteristics

\begin{tabular}{|c|c|c|c|c|c|c|}
\hline Clinical factor & Categories & $n$ & $\begin{array}{l}\text { Summary } \\
\text { WT HLTF } \\
\text { Median (range) }\end{array}$ & $p$-value & $\begin{array}{l}\text { Summary } \\
\text { I21R HLTF } \\
\text { Median (range) }\end{array}$ & $p$-value \\
\hline \multirow[t]{2}{*}{ Age } & Age $<65$ & 57 & 20.7 (2-193) & 0.63 & $2.1(0.7-12.7)$ & 0.54 \\
\hline & Age $>=65$ & 114 & $20.5(1.7-240)$ & & $2.3(0.2-14.3)$ & \\
\hline \multirow[t]{2}{*}{ Sex } & $\mathrm{F}$ & 78 & $20.4(2-121)$ & 0.84 & $2.4(0.2-8.4)$ & 0.71 \\
\hline & M & 93 & $20.6(1.7-240)$ & & $2.2(0.6-14.3)$ & \\
\hline \multirow[t]{2}{*}{ Stage } & । & 121 & $19.6(1.7-240)$ & 0.46 & $2.1(0.2-14.3)$ & 0.91 \\
\hline & $\|$ & 50 & $23.8(3.5-195)$ & & $2.3(0.6-7.6)$ & \\
\hline \multirow[t]{4}{*}{ Histology } & ADC & 122 & $21.5(2-240)$ & 0.061 & $2.3(0.6-14.3)$ & 0.19 \\
\hline & $\mathrm{OTH}$ & 49 & $17.5(1.7-195)$ & & $2.1(0.2-8.4)$ & \\
\hline & $\mathrm{ADC}$ & 122 & $21.5(2-240)$ & 0.09 & $2.3(0.6-14.3)$ & 0.17 \\
\hline & SCC & 42 & $17.5(1.7-195)$ & & $2.1(0.2-7.9)$ & \\
\hline
\end{tabular}

ADC Adenocarcinoma, OTH Other histology types, SCC Squamous cell carcinoma. The Mann-Whitney test was used. A cut-off of $p \leq 0.05$ was used for statistical significance

significant association of each variable with OS and DFS (Table 4).

The association of the combined covariates of WT and I21R HLTF expression with OS and DFS were analyzed by the log-rank test. When considering the four groups, the " Low WT HLTF-High I21R HLTF » group showed a trend for a poorer DFS, but did not reach statistical significance (DFS at 5 years $=25 \%$, log-rank $p=0.067$ ), compared with the three other groups. We thus compared this group (Low WT HLTF-High I21R HLTF) to the three other groups combined. There was no statistical difference in OS (HR 1.26, CI 0.67-2.34; $p=0.48$ ), but the DFS was significantly worse in this group (HR 1.96, CI 1.17-3.30; $p=0.011$ ) (Table 4 and Fig. $4 \mathrm{~d}$ ).

A multivariate analysis (Cox proportional hazard regression model) was performed to include age, sex, stage, histology, and HLTF expression; WT alone (model 1 ), I21R alone (model 2) and the 2 composite groups (model 3) were considered (Table 5). HLTF expression (for each model) was not associated with OS. The expressions of WT (model 1) and I21R HLTF (model 2) were not associated with DFS. However, the shorter DFS of the group "Low WT HLTF-High I21R HLTF » (model 3) as compared with the other groups remained significant (HR 1.98, CI 1.15-3.4, $p=0.014$; Table 5).

\section{Discussion}

The purpose of this study was to assess the expression of WT and variant forms of HLTF mRNAs in NSCLC and evaluate their clinical relevance. Our hypothesis was that the expression of HLTF mRNA variant I21R has a poor prognosis on patients with NSCLC. In head and neck, cervix and thyroid cancers, the expression of HLTF truncated protein has been associated with poor outcome [16-20]. The present study showed that in a cohort of 171 patients, the combination of low expression of WT HLTF transcript and high expression of I21R HLTF transcript was associated with poor prognosis in early stage NSCLC.

Table 3 Association of the composite covariate combining WT HLTF and I21R HLTF expression levels ( $\mathrm{n}$, \%) with patient clinical characteristics

\begin{tabular}{|c|c|c|c|c|c|c|c|}
\hline Clinical factor & Categories & $n$ & $\begin{array}{l}\text { WT }<=20.6 \\
\text { Mut }<=2.23\end{array}$ & $\begin{array}{l}\text { WT }<=20.6 \\
\text { Mut }>2.23\end{array}$ & $\begin{array}{l}\text { WT }>20.6 \\
\text { Mut }<=2.23\end{array}$ & $\begin{array}{l}\text { WT }>20.6 \\
\text { Mut }>2.23\end{array}$ & $p$-value \\
\hline \multirow[t]{2}{*}{ Age } & Age $<65$ & 57 & $20(32.8 \%)$ & 8 (32\%) & $10(45.5 \%)$ & 19 (30.2\%) & 0.62 \\
\hline & Age $>=65$ & 114 & 41 (67.2\%) & 17 (68\%) & 12 (54.5\%) & 44 (69.8\%) & \\
\hline \multirow[t]{2}{*}{ Sex } & $\mathrm{F}$ & 78 & 26 (42.6\%) & $13(52 \%)$ & $11(50 \%)$ & $28(44.4 \%)$ & 0.85 \\
\hline & M & 93 & 35 (57.4\%) & $12(48 \%)$ & 11 (50\%) & 35 (55.6\%) & \\
\hline \multirow[t]{2}{*}{ Stage } & I & 121 & 46 (75.4\%) & 17 (68\%) & 15 (68.2\%) & $43(68.3 \%)$ & 0.81 \\
\hline & $\|$ & 50 & 15 (24.6\%) & $8(32 \%)$ & 7 (31.8\%) & $20(31.7 \%)$ & \\
\hline \multirow[t]{4}{*}{ Histology } & $A D C$ & 122 & $40(65.6 \%)$ & $16(64 \%)$ & 17 (77.3\%) & 49 (77.8\%) & 0.78 \\
\hline & $\mathrm{OTH}$ & 49 & $21(34.4 \%)$ & $9(36 \%)$ & $5(22.7 \%)$ & $14(22.2 \%)$ & \\
\hline & $A D C$ & 122 & 20 (32.8\%) & 8 (32\%) & 10 (45.5\%) & 19 (30.2\%) & 0.35 \\
\hline & SCC & 42 & 41 (67.2\%) & $17(68 \%)$ & $12(54.5 \%)$ & 44 (69.8\%) & \\
\hline
\end{tabular}


Table 4 Univariate analyses of the association of HLTF expression with overall survival and disease-free survival

\begin{tabular}{|c|c|c|c|c|c|c|c|c|c|c|}
\hline \multicolumn{3}{|l|}{ Outcome } & \multicolumn{4}{|l|}{ Overall survival (OS) } & \multicolumn{4}{|c|}{ Disease-free survival (DFS) } \\
\hline Category & & $\mathrm{n}$ & Estimate at 5 years & $\begin{array}{l}\text { Logrank } \\
p \text {-value }\end{array}$ & $\mathrm{HR}(95 \% \mathrm{Cl})^{\mathrm{a}}$ & $\begin{array}{l}\text { Wald } \\
p \text {-value }\end{array}$ & $\begin{array}{l}\text { Estimate } \\
\text { at } 5 \text { years }\end{array}$ & $\begin{array}{l}\text { Logrank } \\
p \text {-value }\end{array}$ & $\begin{array}{l}\mathrm{HR} \\
(95 \% \mathrm{Cl})^{\mathrm{a}}\end{array}$ & $\begin{array}{l}\text { Wald } \\
p \text {-value }\end{array}$ \\
\hline \multirow[t]{2}{*}{ WT } & $<=20.6$ & 86 & $61 \%$ & 0.63 & $1.03(0.97-1.1)$ & 0.34 & $48 \%$ & 0.14 & $1.01(0.95-1.08)$ & 0.72 \\
\hline & $>20.6$ & 85 & $64 \%$ & & & & $61 \%$ & & & \\
\hline \multirow[t]{2}{*}{ I21R } & $<=2.23$ & 83 & $63 \%$ & 0.65 & $1.03(0.92-1.15)$ & 0.61 & $58 \%$ & 0.73 & $1.02(0.93-1.13)$ & 0.64 \\
\hline & $>2.23$ & 88 & $61 \%$ & & & & $49 \%$ & & & \\
\hline \multirow[t]{2}{*}{$\begin{array}{l}\text { Composite } \\
\text { covariable }\end{array}$} & $\begin{array}{l}\text { Wt }>20.6 \text { or } \\
\text { Mut }<=2.23\end{array}$ & 146 & $65 \%$ & 0.47 & $1.26(0.67-2.34)$ & 0.48 & $59 \%$ & 0.0096 & $1.96(1.17-3.3)$ & 0.011 \\
\hline & $\begin{array}{l}\text { Wt }<=20.6 \text { and } \\
\text { Mut }>2.23\end{array}$ & 25 & $50 \%$ & & & & $25 \%$ & & & \\
\hline
\end{tabular}

Cox proportional hazard regression model and log-rank test were used. A cut-off of $p \leq 0.05$ was used for statistical significance

${ }^{a}$ Note: HRs for WT HLTF represent the increase of the hazard for 10 units increase in the WT HLTF

Overall, in silico analysis showed that HLTF alterations, including gene amplifications, high expression, and methylation occurred more frequently in SCC than in ADC. Mutations in HLTF were rare in both ADC and SCC; however, the mutations observed in ADC were different from those found in SCC. In ADC, mutations occur in DNA binding domain and DNA repair domains (Fig. 2), which might alter HLTF transcriptional and
DNA repair abilities. Conversely, in SCC, mutations did not occur in functional domains but there are 2 nonsense mutations leading to the expression of a shorter protein containing only the DBD. This suggests that these shorter proteins would only have transcriptional activity. Further investigations are required to assess the functional consequence and potential clinical impact of these mutations in cancer. Copy number alterations
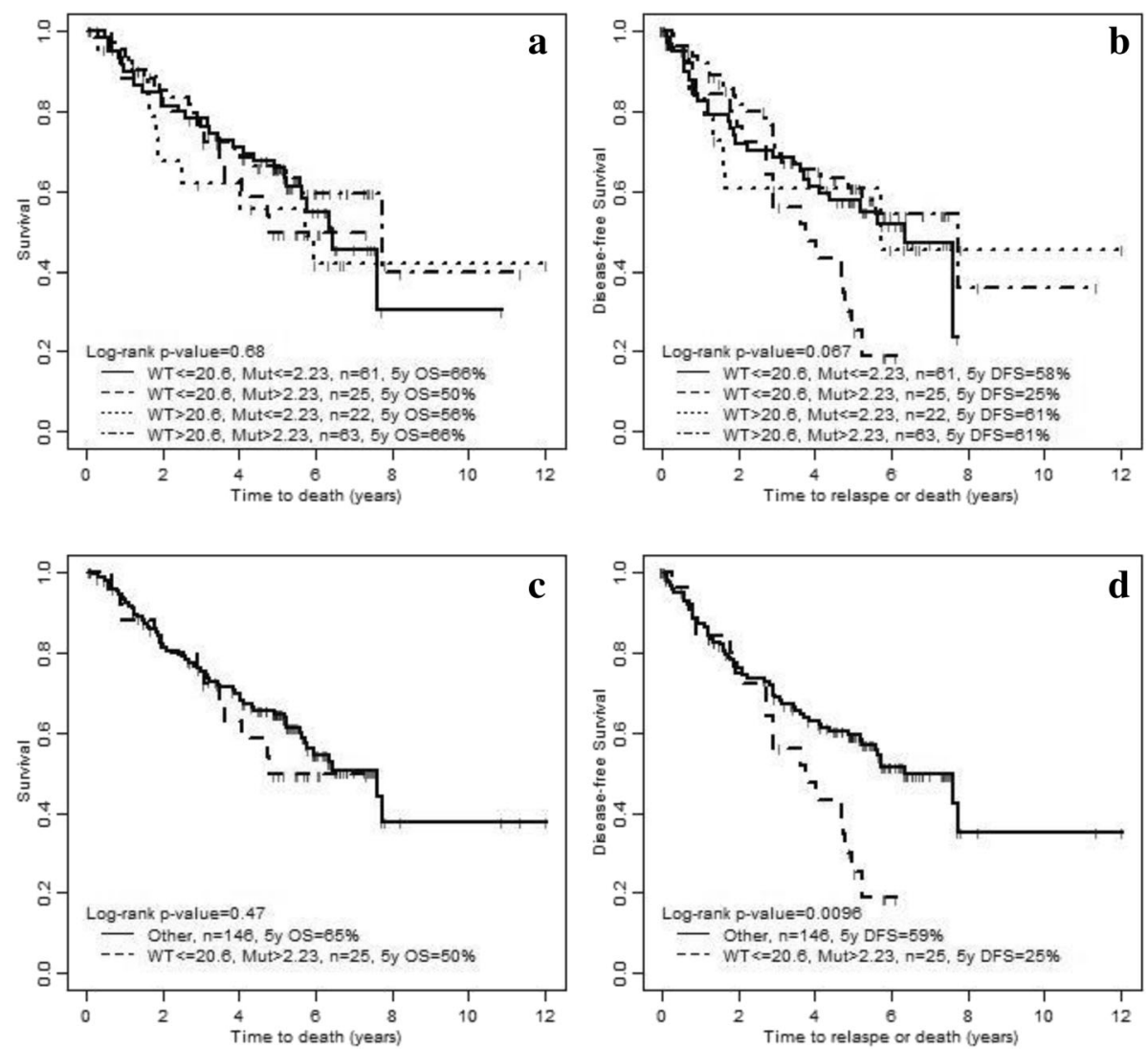

Fig. 4 Association of HLTF expression with OS $(\mathbf{a}, \mathbf{c})$ and DFS ( $\mathbf{b}, \mathbf{d})$. Four groups of patients were built, based on the combined covariates of WT and I21R HLTF expression levels. WT: wild-type HLTF. Mut: I21R HLTF. In A and C, the four groups were considered independent from each other. In C and D, the group "Iow WT HLTF-High I21R HLTF" was compared with the other ones, which were combined in one group called "Other" 
Table 5 Multivariate analyses of the association of HLTF expression with survival and disease-free survival

\begin{tabular}{|c|c|c|c|c|c|c|}
\hline \multirow[t]{2}{*}{ Models $^{a}$} & \multicolumn{3}{|c|}{ Overall survival (OS) } & \multicolumn{3}{|c|}{ Disease-free survival (DFS) } \\
\hline & $\overline{\mathrm{HR}}$ & $95 \% \mathrm{Cl}$ & $p$-value & $\overline{\mathrm{HR}}$ & $95 \% \mathrm{Cl}$ & $p$-value \\
\hline $\begin{array}{l}\text { Model 1: } \\
\text { adjusted effect of WT HLTF (for } 10 \text { units) }\end{array}$ & 1.02 & $0.96-1.08$ & 0.58 & 1 & $0.94-1.06$ & 0.94 \\
\hline $\begin{array}{l}\text { Model 2: } \\
\text { adjusted effect of I21R HLTF }\end{array}$ & 1.01 & $0.9-1.13$ & 0.84 & 1 & $0.9-1.11$ & 0.97 \\
\hline $\begin{array}{l}\text { Model 3: } \\
\text { adjusted effect of HLTF } W T<=20.6 \& I 21 R>2.23 \text { vs. the rest }\end{array}$ & 1.21 & $0.64-2.28$ & 0.56 & 1.98 & $1.15-3.4$ & 0.014 \\
\hline
\end{tabular}

Cox proportional hazard regression model was used. A cut-off of $p \leq 0.05$ was used for statistical significance

${ }^{a}$ All models are adjusted for age, sex, stage and histology

were also found to be different between ADC and SCC; high amplifications were rare in ADC, but $83 \%$ of SCC have either a gain $(57 \%)$ or an amplification (26\%) of HLTF. These observations are consistent with the fact that HLTF is located on chromosome 3q, which is frequently amplified in SCC. We also analyzed the association of HLTF expression with its methylation status in both NSCLC types. In both ADC and SCC, there was a negative correlation between methylation and HLTF expression, but a high expression was more frequently seen in SCC, which might be related to the higher frequency of gene copy number. Intriguingly, we did not notice any difference in HLTF expression levels (WT and I21R) between ADC and SCC by RT-ddPCR. This discrepancy may be possibly explained by the fact that we assessed HLTF mRNA variants separately, while data reported in cBioportal considered only WT HLTF expression without distinguishing the variants.

In the available online data, only WT HLTF expression was assessed. To our knowledge, to date the expression of the HLTF spliced variants with intron 21 retention (I21R) has not been assessed. Using the RT-ddPCR with specific primers that we constructed, we were able to evaluate the expression of WT HLTF mRNA and its spliced variants I21R. Spliced variants I21R lead to the expression of shorter protein forms, which are thought to disturb WT HLTF function and act as oncogene proteins [16]. Studies in head and neck, cervix and thyroid cancers showed that the expression of such shorter proteins was associated with poor prognosis [17-20]. They replace WT HLTF progressively and accumulate along the carcinogenic process, most likely due to their higher stability compared with WT HLTF. It was reported that the I21R transcripts have a lower abundance than the WT HLTF transcript in mouse heart and brain transcriptomes [7, 24]. We analyzed RNA-seq data from TCGA for the presence of the intron 21 sequence and found that its expression was a rare event in NSCLC. In both the NSCLC cell lines and the 171 resected NSCLC from patients, WT HLTF levels were significantly higher than I21R HLTF.

Castro et al. studied the methylation for several genes including HLTF in NSCLC and reported that patients with HLTF methylation have shorter survival [21]; this study represents the only study of HLTF in lung cancer. They reported HLTF methylation frequency for NSCLC and did not observe any significant difference for HLTF methylation between ADC and SCC (12/33 vs. 9/20, respectively; $p=0.57$, Fisher exact test). cBioportal does not provide gene methylation frequency but only correlations with the expression of a given gene. In both ADC and SCC, we observed a negative correlation between HLTF expression and methylation. Interestingly, HLTF expression was affected more by the variation in HLTF copy number than its promoter methylation status.

\section{Conclusion}

So far to our knowledge, our study is the first to assess the clinical impact of WT and variant forms of HLTF expression in patients with NSCLC. TCGA in silico analysis of $H L T F$ alterations including mutations, amplification, and mRNA expression modifications were more frequent in SCC than in ADC. In NSCLC cell lines and patient samples, both the expressions of WT and spliced I21R HLTF mRNAs were detected, but with the latter at lower levels. In a cohort of 171 patients with resected stage I-II NSCLC, the combination of a low WT HLTF expression with a high I21R HLTF expression was associated with shorter DFS both in univariate and multivariate analyses. Surgically resected early stage NSCLC are very heterogeneous and no prognostic factor has been clinically validated for the risk of relapse. Very likely, a panel of several biomarkers will be necessary to predict tumour with poor prognostic; that would therefore require more intensive follow-up and treatment. If validated in independant cohorts, the combination of low WT and high I21R HLTF might belong to this biomarker panel for the prognostic of surgically resected NSCLC. As detailed in a review article we published recently [16], the HLTF gene could be involved in various ways during the stages of tumour initiation and progression, by its ability to alternatively express proteins of different sizes with distinct functions ranging from tumour suppressor 
to oncoprotein. The involvement of alternative RNA splicing in producing tumour promoting proteins is a process that does not require inactivating mutation of a tumour suppressor gene and might be an underestimated carcinogenic mechanism. Further studies should precisely investigate the functions of these HLTF protein forms and their role in cancer development.

\section{Abbreviations}

ADC: Adenocarcinoma; CNA: Copy number alteration; DFS: Disease-free survival; HLTF: Helicase-like transcription factor; HR: Hazard ratio; ICC: Intraclass coefficient; NSCLC: Non-small cell lung cancer; OS: Overall survival; RT-ddPCR: Reverse transcription-droplet digital PCR; SCC: Squamous cell carcinoma; WT: Wild-type

\section{Acknowledgements}

We acknowledge Dr. Claude Lachance for his help in ddPCR design.

\section{Funding}

This work was supported by funds from F. R. S.-FNRS (doctoral research fellowship) (L.D.), Télévie (Al.B., C.M.), FRMH (Fonds pour la Recherche Médicale dans le Hainaut, Belgium) (L.D.) and research grant from Canadian Cancer Society (grant \#701595, MS.T.). C.M. was supported by research funds from Boehringer-Ingelheim Canada. The funding bodies had no role in the design of the study and collection, analysis and interpretation of the data.

\section{Availability of data and materials}

The ddPCR dataset used and analyzed during the current study is available from the corresponding author on reasonable request. In silico analyses were performed with publicly available data from TCGA/cBioportal.

\section{Authors' contributions}

LD and CM designed the study and wrote the manuscript. LD performed RNA extractions with RN and ST, ddPCR, and in silico analyses with EK. MP performed statistical analyses. ArB, FS, AIB, and MST supervised the study and drafted the manuscript. All authors read and approved the final manuscript.

\section{Ethics approval and consent to participate}

The UHN Research Ethics Board approved the study protocol (08-0230-TE) and written informed consent was obtained from each patient. The use of widely available cell lines (ATCC, a publicly accessible repository) does not require ethics approval at our Institution. No permission was required to access the data used for this study.

\section{Consent for publication}

Not applicable.

\section{Competing interests}

The authors declare that they have no competing interests.

\section{Publisher's Note}

Springer Nature remains neutral with regard to jurisdictional claims in published maps and institutional affiliations.

\section{Author details}

'Laboratory of Molecular Biology, Research Institute for Health Sciences and Technology, Université de Mons, Mons, Belgium. ${ }^{2}$ Princess Margaret Research Institute, Princess Margaret Cancer Centre, University Health Network, Toronto, Canada. ${ }^{3}$ Cellular and Molecular Epigenetics, Université de Liège-GIGA, Liège, Belgium. ${ }^{4}$ Biostatistics Department, University of Toronto, Toronto, Canada. ${ }^{5}$ Université Libre de Bruxelles (ULB), Bruxelles, Belgium. ${ }^{6}$ Division of Medical Oncology and Hematology, Princess Margaret Cancer Centre, University Health Network, Toronto, Canada. ${ }^{7}$ Laboratory of Medicine and Pathobiology, University of Toronto, Toronto, Canada. ${ }^{8}$ Department of Muldisciplinary Oncology and Therapeutic Innovations, Assistance Publique des Hôpitaux de Marseille (AP-HM), Aix-Marseille University, Chemin des Bourrely, 13195 Marseille, Cedex 20, France. ${ }^{9}$ Centre de Recherche en Cancérologie de Marseille (CRCM, Cancer Research Center of Marseille),
Inserm UMR1068, CNRS UMR7258 and Aix-Marseille University UM105, Marseille, France.

Received: 14 August 2016 Accepted: 12 March 2018

Published online: 16 April 2018

\section{References}

1. Siegel R, Ma J, Zou Z, Jemal A. Cancer statistics, 2014. CA Cancer J Clin. 2014;64:9-29.

2. Goldstraw P, Crowley J, Chansky K, Giroux DJ, Groome PA, Rami-Porta R, Postmus PE, Rusch V, Sobin L, International Association for the Study of Lung Cancer International Staging Committee, et al. The IASLC lung Cancer staging project: proposals for the revision of the TNM stage groupings in the forthcoming (seventh) edition of the TNM classification of malignant tumours. J Thorac Oncol. 2007;2:706-14.

3. Pujol $J$, Breton $J$, Gervais R, Tanguy M-L, Quoix E, David P, Janicot $H$, Westeel V, Gameroff S, Genève J, et al. Phase III double-blind, placebocontrolled study of thalidomide in extensive-disease small-cell lung cancer after response to chemotherapy: an intergroup study FNCLCC cleo04 IFCT 00-01. J Clin Oncol. 2007:25:3945-51.

4. Tanaka F, Yoneda K. Adjuvant therapy following surgery in non-small cell lung cancer (NSCLC). Surg Today. 2016:46(1):25-37.

5. Mascaux C, Feser WJ, Lewis MT, Barón AE, Coldren CD, Merrick DT, Kennedy TC, Eckelberger Jl, Rozeboom LM, Franklin WA, et al. Endobronchial miRNAs as biomarkers in lung cancer chemoprevention. Cancer Prev Res Phila. 2013;6:100-8.

6. Ding H, Benotmane AM, Suske G, Collen D, Belayew A. Functional interactions between Sp1 or Sp3 and the helicase-like transcription factor mediate basal expression from the human plasminogen activator inhibitor-1 gene. J Biol Chem. 1999;274:19573-80.

7. Helmer RA, Martínez-Zaguilán R, Dertien JS, Fulford C, Foreman O, Peiris V, Chilton BS. Helicase-like transcription factor (hltf) regulates $\mathrm{g} 2 / \mathrm{m}$ transition, wt1/gata4/hif-1a cardiac transcription networks, and collagen biogenesis. PLoS One. 2013:8:e80461

8. Blastyák A, Hajdú I, Unk I, Haracska L. Role of double-stranded DNA translocase activity of human HLTF in replication of damaged DNA. Mol Cell Biol. 2010;30:684-93

9. Motegi A, Liaw H-J, Lee K-Y, Roest HP, Maas A, Wu X, Moinova H, Markowitz $\mathrm{SD}$, Ding $\mathrm{H}$, Hoeijmakers $J \mathrm{HJ}$, et al. Polyubiquitination of proliferating cell nuclear antigen by HLTF and SHPRH prevents genomic instability from stalled replication forks. Proc Natl Acad Sci U S A. 2008;105:12411-6.

10. Sandhu S, Wu X, Nabi Z, Rastegar M, Kung S, Mai S, Ding H. Loss of HLTF function promotes intestinal carcinogenesis. Mol Cancer. 2012;11:18.

11. Moinova HR, Chen W-D, Shen L, Smiraglia D, Olechnowicz J, Ravi L, Kasturi L, Myeroff L, Plass C, Parsons R, et al. HLTF gene silencing in human colon cancer. Proc Natl Acad Sci U S A. 2002;99:4562-7.

12. Bai AHC, Tong JHM, To K-F, Chan MWY, Man EPS, Lo K-W, Lee JFY, Sung JJY, Leung WK. Promoter hypermethylation of tumor-related genes in the progression of colorectal neoplasia. Int J Cancer. 2004;112:846-53.

13. Hibi K, Nakao A. Highly-methylated colorectal cancers show poorlydifferentiated phenotype. Anticancer Res. 2006:26:4263-6.

14. Hibi K, Nakayama H, Kanyama Y, Kodera Y, Ito K, Akiyama S, Nakao A. Methylation pattern of HLTF gene in digestive tract cancers. Int J Cancer. 2003;104:433-6.

15. Philipp AB, Stieber P, Nagel D, Neumann J, Spelsberg F, Jung A, Lamerz R, Herbst A, Kolligs FT. Prognostic role of methylated free circulating DNA in colorectal cancer. Int J Cancer. 2012;131:2308-19.

16. Dhont L, Mascaux C, Belayew A. The helicase-like transcription factor (HLTF) in cancer: loss of function or oncomorphic conversion of a tumor suppressor? Cell Mol Life Sci. 2015;73:129-45.

17. Capouillez A, Decaestecker C, Filleul O, Chevalier D, Coppée F, Leroy X, Belayew A, Saussez S. Helicase-like transcription factor exhibits increased expression and altered intracellular distribution during tumor progression in hypopharyngeal and laryngeal squamous cell carcinomas. Virchows Arch. 2008:453:491-9.

18. Capouillez A, Debauve G, Decaestecker C, Filleul O, Chevalier D, Mortuaire G, Coppée F, Leroy X, Belayew A, Saussez S. The helicase-like transcription factor is a strong predictor of recurrence in hypopharyngeal but not in laryngeal squamous cell carcinomas. Histopathology. 2009;55:77-90.

19. Capouillez A, Noël J-C, Arafa M, Arcolia V, Mouallif M, Guenin S, Delvenne P, Belayew A, Saussez S. Expression of the helicase-like transcription factor and 
its variants during carcinogenesis of the uterine cervix: implications for tumour progression. Histopathology. 2011;58:984-8.

20. Arcolia V, Paci P, Dhont L, Chantrain G, Sirtaine N, Decaestecker C, Remmelink M, Belayew A, Saussez S. Helicase-like transcription factor: a new marker of well-differentiated thyroid cancers. BMC Cancer. 2014;14:492.

21. Castro M, Grau L, Puerta P, Gimenez L, Venditti J, Quadrelli S, SánchezCarbayo M. Multiplexed methylation profiles of tumor suppressor genes and clinical outcome in lung cancer. J Transl Med. 2010;8:86.

22. Forbes SA, Beare D, Gunasekaran P, Leung K, Bindal N, Boutselakis H, Ding M, Bamford S, Cole C, Ward S, et al. COSMIC: exploring the world's knowledge of somatic mutations in human cancer. Nucleic Acids Res. 2015;43:D805-11.

23. Liu C, Tsao MS. In vitro and in vivo expressions of transforming growth factor-alpha and tyrosine kinase receptors in human non-small-cell lung carcinomas. Am J Pathol. 1993;142:1155-62.

24. Helmer RA, Foreman O, Dertien JS, Panchoo M, Bhakta SM, Chilton BS. Role of helicase-like transcription factor (hltf) in the $\mathrm{G} 2 / \mathrm{m}$ transition and apoptosis in brain. PLoS One. 2013;8:e66799.

Submit your next manuscript to BioMed Central and we will help you at every step:

- We accept pre-submission inquiries

- Our selector tool helps you to find the most relevant journal

- We provide round the clock customer support

- Convenient online submission

- Thorough peer review

- Inclusion in PubMed and all major indexing services

- Maximum visibility for your research

Submit your manuscript at www.biomedcentral.com/submit
Biomed Central 